\title{
Conference News
}

\section{HYBRID CIRCUITS, RELIABILITY, APPLICATIONS AND PRODUCTION TECHNIQUES}

A two day meeting will be held in Milan, 5-6 October, 1978 on the above topics. Authors who wish to contribute papers should send a 300 word abstract as soon as possible, preferably before 30 April, 1978, to the Secretariat at:

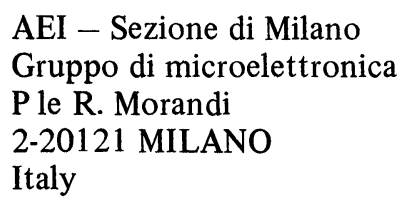

\section{ELECTRONICA 1978}

9-15 November. To be held in Munich at the International Electronics Centre. As well as the Exhibition, a programme of technical sessions will be held on 8th, 9th and 10th November and the 8th International Congress on Microelectronics will be held 13-15 November (working languages for this are English and German). The technical sessions will cover an up-date on mechanical components, modern electronic components (the emphasis being on passive devices), discrete semiconductor components, permanent interconnection technology, quality and reliability of components and finally, an I.E.Z. Forum on "Aspects of International Standardisation of Components". Working languages on the 8th and 9th November will be English and German with the addition of French on the 10th.

The 8th International Congress is concerned with the replacement of mechanical systems by electronic devices. Plenary sessions will be held in the morning with invited papers and contributed papers, whilst in the afternoon, poster sessions are being planned. For further information, please contact:

Münchener Messe und Ausstellungsgesellschaft $\mathrm{mbH}$

Postfach 121009

D 8000 MÜNCHEN 12

F.D.R.

\section{NATIONAL AMERICAN VACUUM SOCIETY SYMPOSIUM}

This will be held in San Francisco 27 November1 December, 1978. Topics of interest and importance to device technologists are always presented at these meetings and for further information please contact:

Paul Holloway or Jerry Nelson

Sandia Laboratories

Division 5825

ALBUQUERQUE

N.M.

U.S.A.

\section{IEEE INTERNATIONAL SOLID STATE CIRCUITS CONFERENCE}

14-16 February 1979. This will be held at the Sheraton Hotel, Philadelphia. Papers will be given covering the design, performance, fabrication, testing and applications of new solid state circuits. Device structure, phenomena and systems will be included. Of particular interest will be the sessions on integrated electronics including monolithic and hybrid, packaging, opto-electronics, microwave electronics, acoustic surface waves and CAD techniques.

For further information please contact conference secretary
Gary Baldwin
Bell Labs.
Holmdel
New Jersey
U.S.A.

\section{2nd EUROPEAN HYBRID MICROELECTRONICS CONFERENCE}

This will be held in Ghent, Belgium, 21-23 May, 1979.

Papers are solicited on recent developments in the whole field of hybrid microelectronics. A 300 word summary of proposed papers should be submitted in 
English by 20 October, 1978, to the Technical Programme Committee Secretary:

Mr. G. K. Steenvoorden

T.H. Delft

Lorentzweg 1

2628 CJ DELFT

Holland

It would be appreciated if the summary emphasised the most important results of the work together with material which is new and original. The conference language is to be English.

An exhibition will be held in conjunction with the conference itself and for further general details please contact the Conference Secretary:

Professor R. Govaerts

Instituut Elektrotechniek K. U. Leuven

Kardinaal Mercierlaan 94

B3030 HEVERLEE

Belgium 

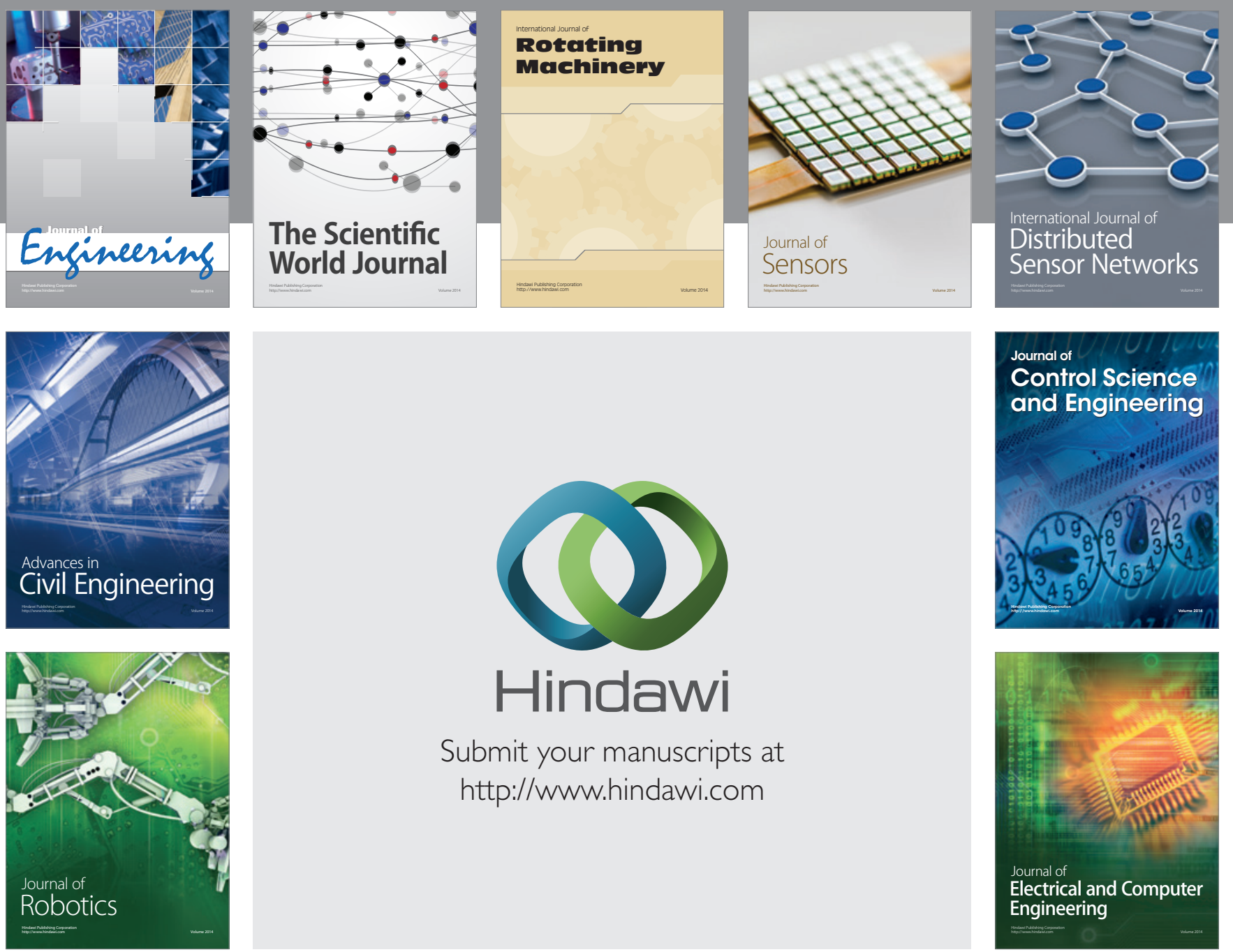

Submit your manuscripts at

http://www.hindawi.com
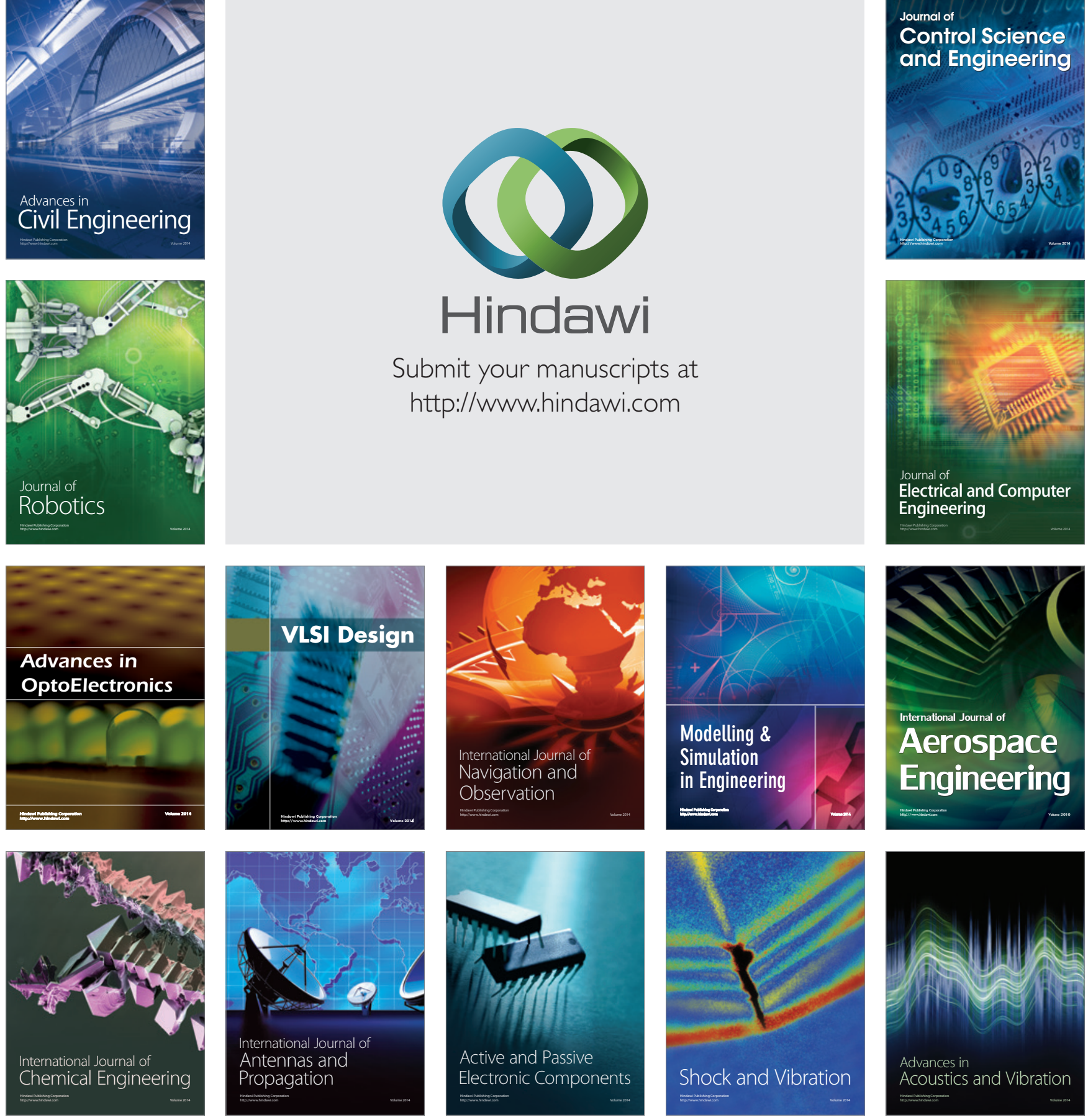